\title{
Automatic platelet counting with the Coulter particle counter
}

\author{
R. E. DAVIS AND R. E. GREEN \\ From the Department of Haematology, Royal Perth Hospital, Western Australia
}

SYNOPSIS A method for accurately counting platelets is described using the Coulter counter model B fitted with a standard $100 \mu$ aperture tube. This enables the counter to be used for red and white cell as well as platelet counts using the same aperture tube. The method uses standard equipment except for a small inexpensive electronic speed controller.

The enumeration of platelets by visual methods is time consuming and tedious; moreover, considerable experience is required to obtain consistently reliable results. To overcome some of these problems a number of methods have been designed for counting platelets using Coulter electronic particle counters. Girling (1962) described a technique using a Coulter model A fitted with a $70 \mu$ aperture tube and counted the platelets in a suspension which also contained some red cells. By counting at two threshold levels figures for total particles and contaminating red cells were obtained. The method had the disadvantage of requiring centrifugation of samples in iced buckets. Eggleton and Sharp (1963) used a $50 \mu$ aperture tube and diluted platelet-rich plasma with $100 \mathrm{ml}$. volumes of saline. Bull, Schneiderman, and Brecher (1965) used a Coulter industrial model B counter (because of its more favourable signal to noise ratio compared with the clinical model B) fitted with a $70 \mu$ aperture tube. They used diluted platelet-rich plasma obtained after separation of the red cells by sedimentation. Eastham (1963) studied the effect of the Bagnold force on diluted whole blood and suggested that with an initial dilution of $1: 12.5$ the recovery of platelets would be almost complete. However, he also used a counter fitted with a small $(70 \mu)$ aperture tube.

These methods all have the disadvantage of using small 50 or $70 \mu$ aperture tubes which mean that where the instrument is required for counting other cell types such as leucocytes the aperture tube must be changed or alternatively a more complex double stand and switching unit must be used. The smaller apertures have a tendency to frequent blockage which is difficult to overcome, and the passage of

Received for publication 8 March 1967. the sample through the aperture is slower than with the larger $100 \mu$ tubes. For these reasons we have not favoured the use of counting systems using small orifice tubes in the routine haematology laboratory.

The method of counting platelets described here uses a Coulter clinical model B counter fitted with a standard $100 \mu$ orifice tube. The instrument is therefore also readily available for most types of routine cell counting. The only other special equipment is an electronic speed control for the centrifuge to give precise control over centrifugation and this is easily constructed or can be obtained at a modest cost. The method uses disposable plastic containers and relatively small volumes of diluent.

\section{MATERIALS AND METHODS}

APPARATUS Coulter counter model B fitted with a $100 \mu$ aperture tube. The instrument was set with an upper

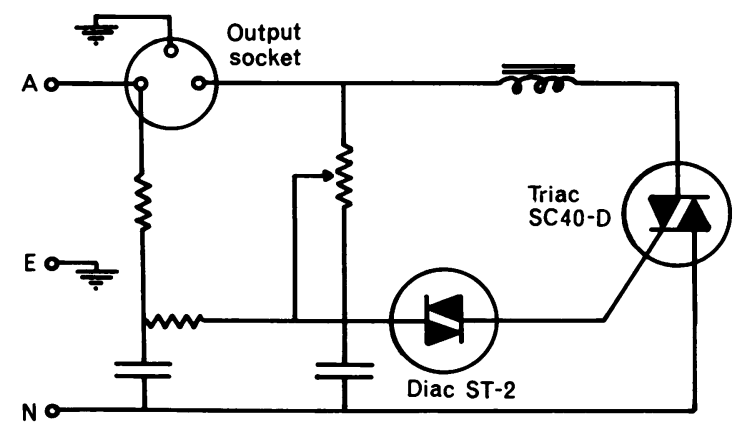

FIG. 1. Circuit of electronic speed control. 
threshold of 15 and a lower threshold of 2 . The amplification and aperture switches were set at $\frac{1}{2}$ and the manometer was set to count a $0.5 \mathrm{ml}$. sample.

An M.S.E. minor centrifuge fitted with $4 \times 50 \mathrm{ml}$. buckets was connected to the power outlet via an electronic speed controller. The unit used a TRIAC silicon gate-controlled A.C. switch which gives greatly improved torque at slow speeds compared with conventional methods of control. Using this device the centrifuge reached the required r.p.m. in about three seconds. The principle of operation is shown in Figure 1.

CONTAINERS One standard type of container was used throughout. It was a flat-bottomed plastic vial with an internal diameter of $23 \mathrm{~mm}$. and a height of $52 \mathrm{~mm}$.; they were fitted with push-on caps ${ }^{1}$. These containers were used as supplied but care was taken to ensure that they were dust free.

DILUENT Saline solution $0.85 \%$ containing $1 \%$ formalin and $0.1 \%$ E.D.T.A. dipotassium salt. The solution was triple filtered through a Millipore membrane filter $(0 \cdot 3 \mu)$ immediately before use.

MACHINE PLATELET COUNTS Blood samples were collected into E.D.T.A., and, after mixing, $0 \cdot 2 \mathrm{ml}$. of the sample was added to $2.3 \mathrm{ml}$. of saline in a plastic container giving an initial dilution of $1: 12.5$. The container was capped and the contents well mixed by inversion. The vial was centrifuged at 900 r.p.m. (R.C.F. $\bumpeq 130$ ) by turning the electronic speed controller until the correct speed had been reached and then immediately switching off. The time taken for acceleration was about three seconds and total centrifugation time 130 seconds. This part of the procedure was critical.

The container was carefully removed from the centrifuge so as not to disturb the button of red cells. The supernatant was further diluted 1 in 200 by delivering $0.1 \mathrm{ml}$. into $20 \mathrm{ml}$. of saline in a plastic vial. After careful mixing by inversion the sample was placed in the counter. A blank count was performed with each batch of tests and did not exceed 1,000. The average of four sample counts, two on each of two separate dilutions, was taken and the blank reading subtracted. The count was then corrected for coincidence error using the standard figures supplied with the machine and the total platelet count calculated using the following formula:-

Number of platelets counted - blank count, corrected for coincidence $\times$ by dilution factor $\times$ volume $=$ platelets per c.mm.

Corrected count $\times 2,500 \times 1 / 500=$ platelets per c.mm.

VISUAL PLATELET COUNTS Visual platelet counts were performed by the method of Dacie and Lewis (1963). Blood was collected into E.D.T.A. and after mixing, diluted 1 in 100 with $3 \%$ trisodium citrate solution containing $1 \%(\mathrm{v} / \mathrm{v})$ formalin. After further mixing, a Neubauer counting chamber was filled with the suspension using a glass capillary. The counting chamber was left in a moist box for 20 minutes before counting to allow the platelets to settle. Platelets were counted using

'Obtained from A.C.I. Plastics, Sydney. a microscope equipped with standard transmitted light (bright field) facilities. All counts were made in duplicate by two technologists giving four counts for each sample.

\section{RESULTS}

Platelet counts were made on 50 separate blood samples. The visual counts were the mean of four counts by two workers. The machine counts were also the mean of four counts. The results are shown in Table I. Visual counts had a range of 23,000 to 746,000 (mean 247,000 per c.mm.) and machine

TABLE I

COMPARISON OF VISUAL AND MACHINE PLATELET COUNTING

\begin{tabular}{|c|c|c|c|c|}
\hline $\begin{array}{l}\text { Sample } \\
\text { No. }\end{array}$ & $\begin{array}{l}\text { Mean Visual } \\
\text { Count } \\
(1,000 / \text { c.mm. })\end{array}$ & $\begin{array}{l}\text { Mean Machine } \\
\text { Count } \\
(1,000 / \text { c.mm. })\end{array}$ & $\begin{array}{l}\text { Difference } \\
(1,000 / \text { c.mm. })\end{array}$ & $\begin{array}{l}\text { Difference } \\
(\%)\end{array}$ \\
\hline 1 & 76 & 73 & -3 & -3.95 \\
\hline 2 & 63 & 68 & +5 & $+7 \cdot 4$ \\
\hline 3 & 411 & 424 & +13 & $+3 \cdot 16$ \\
\hline 4 & 185 & 206 & +21 & $+11 \cdot 3$ \\
\hline 5 & 138 & 122 & -16 & -11.6 \\
\hline 6 & 185 & 186 & +1 & +0.53 \\
\hline 7 & 502 & 496 & -6 & -1.2 \\
\hline 8 & 589 & 640 & +51 & +8.67 \\
\hline 9 & 98 & 102 & +4 & +4.07 \\
\hline 10 & 509 & 490 & -19 & -3.74 \\
\hline 11 & 151 & 126 & -25 & $-16 \cdot 6$ \\
\hline 12 & 216 & 208 & -8 & -3.7 \\
\hline 13 & 277 & 297 & +20 & +6.74 \\
\hline 14 & 90 & 98 & +8 & +8.9 \\
\hline 15 & 366 & 387 & +21 & +5.74 \\
\hline 16 & 313 & 299 & -14 & -4.47 \\
\hline 17 & 176 & 191 & +15 & +8.5 \\
\hline 18 & 99 & 94 & -5 & -5.05 \\
\hline 19 & 156 & 152 & -4 & $-2 \cdot 56$ \\
\hline 20 & 99 & 87 & -12 & $-12 \cdot 2$ \\
\hline 21 & 266 & 283 & +17 & +6.4 \\
\hline 22 & 186 & 167 & -19 & -10.4 \\
\hline 23 & 307 & 309 & +2 & +0.65 \\
\hline 24 & 228 & 264 & +36 & +15.8 \\
\hline 25 & 746 & 749 & $\begin{array}{r}+3 \\
\end{array}$ & +0.4 \\
\hline 26 & 248 & 261 & +13 & +5.24 \\
\hline 27 & 692 & 782 & +90 & +13.0 \\
\hline 28 & 198 & 186 & -12 & -6.06 \\
\hline 29 & 296 & 272 & -24 & -8.1 \\
\hline 30 & 71 & 79 & +8 & $+11 \cdot 3$ \\
\hline 31 & 65 & 69 & +4 & +6.15 \\
\hline 32 & 235 & 236 & +1 & +0.425 \\
\hline 33 & 240 & 251 & +11 & +4.6 \\
\hline 34 & 152 & 158 & +6 & $\begin{array}{r}3.95 \\
\end{array}$ \\
\hline 35 & 44 & 52 & +8 & $+18 \cdot 2$ \\
\hline 36 & 431 & 451 & +20 & +4.64 \\
\hline 37 & 446 & 436 & -10 & $-2 \cdot 24$ \\
\hline 38 & 152 & 153 & +1 & +0.66 \\
\hline 39 & 85 & 91 & +6 & +7.05 \\
\hline 40 & 257 & 242 & -15 & -5.84 \\
\hline 41 & 200 & 192 & -8 & -4.0 \\
\hline 42 & 225 & 232 & +7 & $+3 \cdot 12$ \\
\hline 43 & 145 & 163 & +18 & +12.4 \\
\hline 44 & 385 & 368 & -17 & -4.53 \\
\hline 45 & 591 & 538 & -53 & -8.95 \\
\hline 46 & 111 & 120 & $\begin{array}{r}+9 \\
+9\end{array}$ & $\begin{array}{r}8.19 \\
+\end{array}$ \\
\hline 47 & 252 & 255 & +3 & +1.19 \\
\hline 48 & 60 & 62 & +2 & $\begin{array}{r}+33 \\
\end{array}$ \\
\hline 49 & 23 & 25 & +2 & +8.7 \\
\hline 50 & 292 & 299 & $\begin{array}{r}1 \\
+\quad 7\end{array}$ & $\begin{array}{r}2.4 \\
+\quad 2\end{array}$ \\
\hline Mean & 247 & 250 & & \\
\hline
\end{tabular}

S.E. of difference between the two means, $34(2 \times 34 \gg 3)$. 


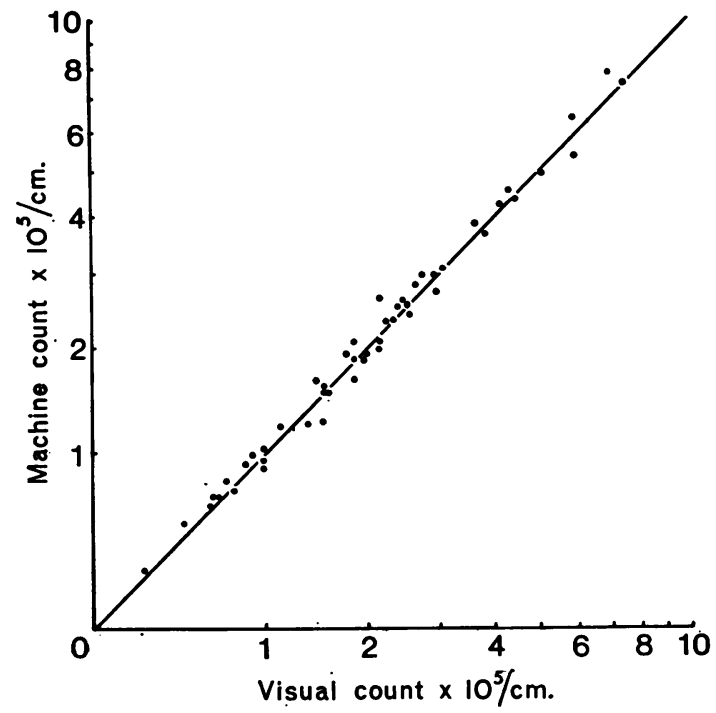

FIG. 2. Comparison of visual and machine platelet counts.

counts a range of 25,000 to 782,000 (mean 250,000 per c.mm.); the standard error of the difference between the means, $34(2 \times 34 \gg 3)$, was not significant. The relationships of the results obtained by both methods is shown in Figure 2 .

To test the repetitive accuracy of the method the

TABLE II

RESULTS OF 12 REPEATED MACHINE PLATELET COUNTS ON A SINGLE BLOOD SAMPLE

Count per c.mm.

\begin{tabular}{cc}
\hline 315,500 & 290,000 \\
292,500 & 316,000 \\
316,000 & 307,000 \\
313,000 & 302,000 \\
291,000 & 293,000 \\
320,000 & 298,000 \\
Mean 304,500 & \\
Standard deviation 11,000 & \\
Coefficient of variation 3.6\% &
\end{tabular}

platelets in a single blood sample were counted 12 times; the results ranged from 291,000 to 320,000 (Table II) (mean 304,500 per c.mm.).

\section{DISCUSSION}

An automatic method suitable for routinely counting platelets should ideally use equipment compatible with other routine haematological measurements. Methods previously described have been suitable for special application and perhaps for individual laboratories, but none have gained wide acceptance. The method outlined uses standard equipment with the exception of a small electronic speed controller; results are very close to the best visual counts and repetitive accuracy of the method is high.

Final platelet numbers presented to the counter depend on the initial sample dilution and the speed and duration of centrifugation. We were able to confirm Eastham's (1963) finding that an initial sample dilution of $1: 12.5$ gave optimal platelet recovery. Standard speed controls were not found satisfactory because of slow acceleration. With the electronic method of control the required speed is reached in a few seconds and the centrifuge can be operated at slow but precisely predictable speeds as required. The final suspension to be counted is not entirely free of red cells but their numbers are not sufficient to influence the platelet count and the dual threshold facility in the Coulter model B counter effectively screens these out.

We wish to thank Dr. H. J. Woodliff for his encouragement and advice, and Miss Jerri Thomssen for assistance.

\section{REFERENCES}

Bull, B. S., Schneiderman, M. A., and Brecher, G. (1965). Amer. J. clin. Path., 44, 678.

Dacie, J. V., and Lewis, S. M. (1963). Practical Haematology, 3rd ed. Churchill, London.

Eastham, R. D. (1963). J. clin Path., 16, 168.

Eggleton, M. J., and Sharp, A. A. (1963). Ibid., 16, 164.

Girling, J. H. (1962). J. med. Lab. Technol., 19, 168. 